\title{
A RELEVÂNCIA DO ENSINO DE SOCIOLOGIA E DE FILOSOFIA PARA A FORMAÇÃO DOS JOVENS NO SÉCULO XXI
}

\author{
A. M. ARAÚJO e J. G. S. A. LIMA \\ Instituto Federal de Educação, Ciência e Tecnologia do Rio Grande de Norte \\ jose.avelino@ifrn.edu.br*
}

Artigo submetido em julho/2015 e aceito em julho/2015

DOI: $10.15628 /$ holos.2015.3223

\section{RESUMO}

O presente texto busca problematizar esse "preconceito pedagógico", abrindo espaço para um debate endereçado ao entendimento dos conhecimentos sociológicos e filosóficos como saberes constitutivos de uma das principais funções sociais da escola, qual seja: a da educação para o exercício da cidadania. Trazemos, ainda, a discussão sobre a especificidade da Sociologia e da Filosofia no âmbito do Ensino Médio, compreendendo essas disciplinas como integrantes de um projeto educacional alicerçado na construção de um "conhecimento prudente para uma vida decente", como nos ensina, hoje, Boaventura de Sousa Santos (2006).

PALAVRAS-CHAVE: Educação; Juventude; Sociologia; Filosofia.

\section{THE SOCIOLOGY TEACHING THE RELEVANCE AND PHILOSOPHY FOR TRAINING OF YOUNG PEOPLE IN XXI CENTURY}

\begin{abstract}
This paper seeks to question this "pedagogical prejudice", making room for a debate addressed to the understanding of the sociological and philosophical knowledge as constitutive knowledge of one of the main social functions of the school, namely: the education for
\end{abstract}

citizenship. We bring also the discussion of the specificity of Sociology and Philosophy in the School, including such disciplines as members of an educational project founded to build a "prudent knowledge for a decent life," as teaches us today, Boaventura de Sousa Santos (2006).

KEYWORDS: Education; Youth; Sociology; Philosophy. 


\section{PRIMEIRAS PALAVRAS}

Iluminar o obscuro, humanizar o mundo, aceder à dignidade da humanitas, são aspectos diferentes de uma única coisa: a instituição do mundo comum. Anne-Marie Roviello

No ano de 2006, as disciplinas Sociologia e Filosofia se tornaram obrigatórias na estrutura curricular do Ensino Médio brasileiro. Desde então, muitas discussões foram geradas em torno da importância dos conhecimentos de cada uma dessas disciplinas em face da formação intelectual e humanística dos estudantes. Apesar disso, as referidas disciplinas ainda sofrem uma espécie de "marginalização curricular", através da qual seus conhecimentos são estigmatizados como puro verbalismo teórico desvinculado das realidades concretas em que vivem os jovens.

O presente texto busca problematizar esse "preconceito pedagógico", abrindo espaço para um debate endereçado ao entendimento dos conhecimentos sociológicos e filosóficos como saberes constitutivos de uma das principais funções sociais da escola, qual seja: a da educação para o exercício da cidadania. Trazemos, ainda, a discussão sobre a especificidade da Sociologia e da Filosofia no âmbito do Ensino Médio, compreendendo essas disciplinas como integrantes de um projeto educacional alicerçado na construção de um "conhecimento prudente para uma vida decente", como nos ensina, hoje, Boaventura de Sousa Santos (2006).

Com esse pensamento, consideramos que tanto a Sociologia como a Filosofia oportunizam aos estudantes o contato com formas de conhecimento cujas dimensões políticas de seu ensino são capazes de desencadear uma leitura crítica, reflexiva e desnaturalizada sobre a realidade social, contribuindo, nesse sentido, para o estabelecimento da justiça social e para o enriquecimento das capacidades humanas quanto à manutenção da vida e da dignidade das pessoas.

\section{POR UMA EDUCAÇÃO PARA O ESTRANHAMENTO E A DESNATURALIZAÇÃO DAS RELAÇÕES SOCIAIS: SOCIOLOGIA E ENSINO MÉDIO}

Abordar a importância do ensino de Sociologia na Educação Básica implica, inicialmente, no reconhecimento de que esse debate reflete, em menor ou em maior grau, um histórico curricular profundamente marcado por ausências e presenças, dessa disciplina, no âmbito do que hoje denominamos Ensino Médio. Tal intermitência provocou, dentre muitos aspectos, a dificuldade da construção de uma "identidade pedagógica" para a Sociologia no currículo da Educação Básica, dificultando, de igual modo, a percepção de sua especificidade epistemológica diante das demais disciplinas, qual seja: o estudo dos fenômenos sociais produzidos a partir das relações estabelecidas pelos indivíduos na sociedade.

Assim, decorrente dessa falta de "identidade pedagógica", a Sociologia sofreu - e ainda sofre - um processo de estigmatização que lhe confere o status de "não-lugar" no interior da estrutura curricular da escola de nível médio brasileira, contribuindo para o fortalecimento de inúmeros preconceitos que a caracterizam como um conhecimento abstrato e de pouca ou quase nenhuma utilidade prática para a vida concreta dos estudantes.

Além disso, e em função do pouco prestígio escolar que envolve a Sociologia, esse componente curricular acabou por transformar-se, em muitas realidades socioeducacionais, em uma "disciplina-apêndice", cuja "importância" está diretamente relacionada ao complemento da 
carga horária de profissionais de educação não licenciados para o ensino dos conhecimentos sociológicos.

Nesse sentido,

a percepção é de que a disciplina ainda não conseguiu se firmar como componente curricular do Ensino Médio, sendo na maioria das vezes, vista como um complemento da carga horária, podendo ser ministrada por profissionais de outras áreas sem prejuízo para o aprendizado dos alunos (VIEIRA; CUNHA, 2014, p. 9).

Essa representação depreciativa da Sociologia, arraigada em muitas configurações escolares, contribui para distanciar os alunos de seus próprios mundos de vida, já que é no espaçotempo desse componente curricular onde podem ser desencadeadas significativas situações de ensino e de aprendizagem endereçadas à problematização da complexa rede de relações sociais, culturais e políticas que circunda a comunidade, a escola e seus sujeitos.

Diante dessa perspectiva, a Sociologia tem um importante papel político-epistemológico no campo educacional, uma vez que permite, do ponto de vista epistemológico, o permanente exercício da "imaginação sociológica" (MILLS, 1982), isto é, um tipo de racionalidade fundamentada nas práticas do estranhamento e da desnaturalização das práticas sociais. Por outro lado, também propicia o uso político do conhecimento sociológico em favor da intervenção na sociedade, buscando a formação da autonomia de pensamento e estimulando a ação consciente e transformadora em face das inúmeras manifestações de opressão social que marcam e desumanizam a vida de muitas pessoas (FREIRE, 2005).

Nesse raciocínio, cabe pontuar que a Sociologia, como espaço privilegiado para a realização das Ciências Sociais no Ensino Médio, oportuniza aos estudantes a adoção de novas lentes para a interpretação da realidade, possibilitando a construção de novos modos de pensar as práticas sociais em suas plurais formas de manifestação.

Dois princípios são fundamentais para o satisfatório desenvolvimento dessa perspectiva, os quais, conforme acreditamos, possibilitam perceber a especificidade da Sociologia perante as outras disciplinas integrantes da estrutura curricular do Ensino Médio. São eles: o estranhamento e a desnaturalização.

O princípio do estranhamento, embora não seja exclusivo da Sociologia, busca provocar nos estudantes a capacidade de espanto diante de situações sociais consideradas corriqueiras, comuns, triviais (BRASIL, Orientações Curriculares para o Ensino Médio, 2006). Assim, as teorias e os conceitos sociológicos configuram-se como "operadores cognitivos" fundamentais ao exercício de problematização científica daqueles fenômenos sociais que não são imediatamente conhecidos/interpretados por apresentarem um caráter supostamente "normal".

O estranhamento é a condição necessária para os jovens do ensino médio realizarem uma leitura sociológica do mundo. Estranhar os fenômenos sociais exige que o professor provoque inquietação na turma. [...] Exige dos alunos critério para desvendar a realidade, ousadia para abandonar as explicações já consagradas e elaborar respostas coerentes e racionais para os fenômenos sociais (GUIMARÃES, 2014, p. 26-27). 
O princípio da desnaturalização tem por objetivo entender os fenômenos sociais como resultados da atividade humana em sociedade. Com isso, a Sociologia permite aos estudantes a percepção do caráter histórico das estruturas e dinâmicas sociais, buscando a contestação/desconstrução de concepções e explicações naturalizadoras ${ }^{1}$ que ofuscam a historicidade das relações e práticas sociais.

A atitude de desnaturalização da sociedade realizada pela Sociologia requer, pois,

[...] o desmonte de argumentos popularmente incontestáveis; o rompimento com concepções aceitas como normais; a contrariedade em relação à expectativa de situações naturalmente esperadas até mesmo pelos jovens, a despeito de toda energia renovadora da idade. Desnaturalizar é tratar os fenômenos sociais a partir de sua historicidade; é entender que a vida em sociedade não está dada: é o resultado da atividade humana (GUIMARÃES, 2014, p. 26, grifo da autora).

No horizonte dessa argumentação, os encadeamentos recíprocos entre estranhamento e desnaturalização demarcam a especificidade do ensino de Sociologia na escola de nível médio, cumprindo o importante papel quanto ao desenvolvimento da imaginação sociológica, habilidade intelectual capaz de promover o rompimento com as percepções ingênuas sobre a realidade social, além de possibilitar aos estudantes o protagonismo diante da construção de uma visão de mundo mais ampla e cada vez mais crítico-reflexiva.

Assim entendida, a Sociologia no Ensino Médio oferece aos jovens referenciais próprios de análise para que estes possam "sentir o jogo que se processa entre os homens e a sociedade, a biografia e a história, o eu e o mundo" (MILLS, 1982, p. 10). Desse modo, a inserção da Sociologia no âmbito curricular da Educação Básica traz para os professores o compromisso precípuo de provocar nos estudantes o estranhamento e a desnaturalização das situações sociais por eles vivenciadas.

\begin{abstract}
No ensino médio, uma das responsabilidades do professor de Sociologia é desenvolver, no aluno, a capacidade de problematizar o mundo a sua volta. Incentivá-lo a perceber situações que fazem parte de sua convivência como, por exemplo, a falta de interesse do governo local em atender às demandas de sua escola ou de seu bairro, ou ainda, a violência física, praticada, cotidianamente, no ambiente escolar. Provocar o estranhamento e a desnaturalização é desenvolver a sensibilidade do aluno para enxergar sociologicamente o mundo, a partir de diferentes questões que o cercam diariamente (GUIMARÃES, 2014, p. 27).
\end{abstract}

Com esse pensamento, a Sociologia, como porta-voz das Ciências Sociais no ensino básico, propicia ao estudante o contato com sistemas de conhecimentos sobre o mundo social capazes de suscitar uma postura crítica, reflexiva e atuante diante das relações e práticas humanas. Nesse prisma, as perspectivas sociológicas, antropológicas e políticas transformam-se em importantes referenciais cognitivos através dos quais os alunos podem ler os fenômenos societários, interpretálos, problematizá-los e, em alguns casos, atuar sobre eles.

\footnotetext{
1 "Efeito de naturalização: fazer parecerem naturais certas construções sociais; por exemplo: a dominação masculina fundamentada em uma possível superioridade biológica" (BRASIL, Orientações Curriculares para o Ensino Médio, p. 105).
} 
Cabe sinalizar, a partir desse raciocínio, que o estudo da Sociologia no Ensino Médio pode despertar e potencializar, nos estudantes, a capacidade para uma leitura racional e coerente do mundo em que vivem, tendo em vista que o uso do conhecimento historicamente elaborado por essa disciplina deve

[...] provocar o estranhamento e a desnaturalização em relação às questões sociais que estão mais próximas do jovem, e que assumem significado em sua vida, exercitam sua sensibilidade em relação às contradições sociais que 0 aguardam no mundo fora da escola (GUIMARÃES, 2014. p. 31).

No âmago dessa discussão, acreditamos, por fim, que a Sociologia no Ensino Médio oportuniza uma experiência intelectual instigante e prazerosa, ao mesmo tempo em que provoca questionamentos em torno de certezas e visões de mundo ainda muito arraigadas em nosso espírito individual e coletivo. Dessa maneira, as aulas constituintes desse componente curricular abrem novos horizontes para compreendermos e problematizarmos o nosso "estar sendo no mundo", como também consentem aprendizados para a contínua reelaboração da nossa humanidade em tempos de desencanto social. Com isso, a Sociologia reaviva nos indivíduos, conforme nos ensina Antônio Candido, a "quota de humanidade, na medida em que os torna mais compreensivos e abertos para a natureza, a sociedade, o semelhante" (CANDIDO, 1995, p. 242).

\section{POR UMA EDUCAÇÃO PARA FILOSOFAR SOBRE O MUNDO: FILOSOFIA E ENSINO MÉDIO}

Talvez não seja um exagero dizer que tanto o ensino da Filosofia quanto o da Sociologia apresenta a sua relevância na formação dos jovens para além das exigências das provas e exames nacionais que condicionam a entrada desses jovens no ensino superior ou mesmo para além produção de instrumentos úteis ao cotidiano.

Já no Séc. XIX, o modo de se relacionar com a Filosofia como um saber a ser decorado foi veementemente denunciado pelo filósofo alemão Friedrich Nietzsche como tendo uma finalidade que, ao invés de conduzir a uma autêntica formação do espírito (Bildung), levou, antes, a um "desprezo" pela Filosofia. Esse desprezo, segundo Nietzsche, se deu em função de a mesma ser apresentada de modo meramente "enciclopédico", cujos princípios deveriam ser decorados apenas como meio para a realização de exames, para, logo em seguida, serem esquecidos.

Poderíamos dizer que esse modo de se tomar a Filosofia, como um saber "enciclopédico" distante de tudo o que se vive, e que foi devidamente denunciado por Nietzsche, corresponde, nos dias atuais, talvez, menos à tarefa realizada pelos que se empenham na atividade filosófica, do que propriamente à compreensão equivocada daqueles que, ao desconhecerem a relevância da Filosofia e da Sociologia para a formação humana, acusam-nas de serem, em parte, as responsáveis por um currículo "não atrativo", e, desse modo, defendem a sua retirada do currículo escolar; ou, sob uma hipótese menos radical, consideram que essas disciplinas devam ser oferecidas aos alunos do Ensino Básico como uma espécie de "menu" a ser escolhido ao gosto de cada um.

No que se segue, apresentamos as razões pelas quais tal compreensão a respeito do ensino da Filosofia, como um ensino abstrato, inútil, e, por isso mesmo, sem interesse, não corresponde ao real sentido dessa disciplina para a vida humana, de modo muito especial na vida dos jovens, 
na medida em que, por meio da reflexão filosófica, é descortinado um horizonte de sentido constitutivo de qualquer formação que se pretenda autônoma, crítica e, sobretudo, ética.

Por um lado, a acusação de que o ensino de Filosofia é uma disciplina "sem interesse" por parte dos jovens, coloca, de saída, uma questão que, por não ter suas razões devidamente explícitas, transparentes, desperta uma desconfiança acerca dos pressupostos (políticos) subjacentes à essa acusação levando-os, desse modo, a ser inteiramente questionáveis. Por outro lado, para aqueles que lidam diretamente com a Filosofia, seja no Ensino Básico, seja no ensino superior, é evidente que tal acusação também é fruto de preconceitos que se ergueram ao longo da tradição em torno da mesma; preconceitos que, nos dias de hoje, tendem a ser finalmente selados pelos discursos daqueles que, ignorando a dimensão formativa da Filosofia para o ser humano, se renderam ao imediatismo e ao pragmatismo que o estilo de vida comporta atualmente; estilo esse totalmente destituído de uma postura crítica sobre o mundo. De igual modo, problematizamos a instrumentalização do ensino na Sociologia que, a exemplo da Filosofia, passa por processos de afirmação de identidade curricular que incidem diretamente nas dinâmicas pedagógicas que se desdobram na atmosfera da escola de nível médio.

Outra questão que se coloca como um obstáculo à compreensão acerca da relevância da Filosofia para a formação dos jovens é aquela que concerne à própria questão da definição do conceito de Filosofia. Como apresentar a relevância dessa disciplina sem determinar com precisão a sua natureza e o seu método específico? É bem verdade que, ao longo da tradição filosófica, múltiplas foram as definições dadas ao conceito "filosofia" e, conforme enfatizaram os Professores Danilo Marcondes e Irley Franco,

no contexto contemporâneo não mais vemos as diferentes respostas como excludentes ou como exigindo uma adesão total [...]. Vivemos uma época de pluralismo das ideias, e isso nos permite examinar os vários caminhos que se abrem diante de nós [...] (MARCONDES; FRANCO, 2011, p. 7-8).

O que podemos dizer a respeito do sentido da Filosofia, é que tal sentido é amplo e variável segundo o ponto de vista de cada filósofo ou escola filosófica; que esses sentidos não se excluem mutuamente, nem exigem uma adesão plena, visto não haver um critério pelo qual se possa defender um sentido em detrimento do outro (MARCONDES; FRANCO, 2011). Todavia, tal compreensão a respeito do sentido da Filosofia não retira o seu caráter de um pensamento rigoroso e exigente, no qual se busca justificar, por meio de argumentos, as razões e os princípios daquilo que é afirmado sobre as diversas instâncias do que entendemos por "real".

Se entendemos que o filosofar é muito mais do que apenas saber o que os outros pensaram, e se entendemos que o nosso tempo nos coloca questões as quais escapam das respostas dadas pelas ciências, podemos antever, a partir disso, que a reflexão filosófica abre as possibilidades de elucidação dos sentidos dessas questões, ainda que não possa esgotar totalmente o seu sentido. Por outro lado, ainda que a Filosofia não se esgote nas respostas que os filósofos deram aos problemas do passado, o modo com que esses filósofos pensaram esses problemas pode ser de grande valia para nós, hoje, não para que repitamos suas possíveis propostas de solução, o que não faria sentido; mas para que, levando em conta o horizonte heurístico da reflexão descortinado pelos mesmos, possamos pensar com maior propriedade as nossas questões. 
De modo geral, dentre todos os sentidos atribuídos à Filosofia, uma característica parece ser comum a todos eles, e que, em certa medida, marca aquilo que é específico do fazer filosófico, a saber: a sua relação com o conceito. Essa afirmação, contudo, ainda nos parece vaga. Como se constitui esse tipo de relação? Um dos mais importantes filósofos da modernidade, Immanuel Kant, chegou a caracterizar a Filosofia, à diferença da matemática, como um "conhecimento racional por análise de conceitos" 2 . Segundo Kant, esse seria o conceito escolástico da Filosofia, no sentido como é tomado pelas escolas filosóficas e que visa a uma maior sistematização do conhecimento.

Na medida em que não podemos abrir mão da investigação conceitual, investigação essa esclarecedora das diversas dimensões de experiência humana: cognitiva, ética, estética, etc., é que a Filosofia se torna imprescindível para uma sociedade que se propõe a formar criticamente os seus futuros cidadãos.

Acusado de corromper a juventude de Atenas, o grande filósofo grego, Sócrates, como sabemos, foi condenado à morte por chamar a atenção dos jovens atenienses para que esses, fazendo uso de sua razão, pudessem investigar a respeito do real sentido de suas experiências e, desse modo, pudessem alcançar um conhecimento mais adequado a respeito do que orientava a vida deles, libertando-se, desse modo, dos preconceitos correntes da sociedade da época. Foi exatamente por não abrir mão desse ideal na formação dos jovens atenienses que Sócrates teve de pagar com a própria vida.

Sócrates indicou, por meio da busca pelo esclarecimento conceitual, que é possível elucidar o verdadeiro sentido das nossas experiências, de modo a levar a compreensão acerca das suas condições, do seu alcance, bem como dos seus limites, assumindo, a partir daí, uma postura ética em face à vida.

Antes mesmo da atuação de Sócrates, podemos dizer que o próprio nascimento da Filosofia foi marcado pelo vislumbre de um povo (Grécia, Séc. VI a.C) que, tomando consciência de seu poder questionador, decidiu libertar-se de todas as formas de tirania, legitimada pelos mitos e dogmas da tradição, descobrindo, em seu poder reflexivo (logos), a fonte da sua liberdade.

A própria etimologia da palavra "filosofia", como "amor à sabedoria", "desejo da sabedoria", nos indica algo que é próprio ou característico da reflexão filosófica: o seu caráter de "investigação crítica", de "busca", ao invés da posse de um pretenso saber, da afirmação dogmática de alguma "verdade". Assim, não obstante as múltiplas definições dadas ao seu conceito, podemos identificar algo que é comum a todas elas e que caracteriza a Filosofia como uma "atividade", como uma "experiência de pensamento", de investigação crítica daquilo que se busca compreender, uma busca pela compreensão ou elucidação do próprio sentido das questões que a razão humana levanta.

Alguém poderia levantar a seguinte objeção: para que serve afinal de contas a Filosofia se ela não fornece nenhuma resposta para as questões que ela levanta? Talvez uma possível resposta a essa objeção seja a de que por meio da elucidação das questões que à nossa razão se coloca e ainda que não obtenhamos respostas definitivas para as mesmas, ao pensar sobre elas, a reflexão pode nos conduzir a uma autotransformação no nosso pensamento e, quiçá, de nossas ações; do

\footnotetext{
${ }^{2}$ Cf. KANT, I. Lógica. Ak 24: “A filosofia é, pois, o sistema dos conhecimentos filosóficos ou dos conhecimentos racionais a partir de conceitos" (p. 41).
} 
modo como nos relacionamos conosco mesmo, com os outros e com o mundo, fazendo-nos refletir sobre que tipo de pessoa desejamos ser no mundo. É, portanto, um sentido ético, de sabedoria de vida, que a reflexão filosófica pode oferecer àqueles que a ela se dedicam. E isso não com respostas prontas, mas com o despertar para uma atitude livre e autônoma em face ao mundo.

Se, pois, consideramos que a adolescência é um estágio no qual os jovens passam por momento de crises, conflitos, descobertas, quanto ao sentido de suas vidas e ao que se apresenta como alternativa para esse sentido, ao seu modo de ser, etc., e, se o pensar filosófico, como bem indicaram Platão e Aristóteles, se inicia com o "Thauma" (espanto, admiração, perplexidade), dando origem à reflexão despertada pelo estranhamento das coisas, do não conhecido ou mesmo tido como óbvio, poderíamos dizer que a Filosofia é uma atividade privilegiada para ajudar os adolescentes a lidar, de uma maneira livre e crítica, com tudo aquilo que se apresenta a eles como supostas "alternativas" prontas de modelos de vidas a serem seguidos.

Em outras palavras, se consideramos que os adolescentes são aqueles que estão numa fase de questionamentos e descobertas acerca dos sentidos de suas experiências cognitivas, afetivas, valorativas, etc., e, se tomamos a Filosofia em seu caráter dinâmico de atividade de questionamentos e elucidação conceitual sobre o sentido das coisas em geral, atividade a partir da qual é possível uma maior clareza a respeito dos fundamentos e princípios que constituem aquelas experiências humanas, então, desse modo, temos que admitir que a relevância do ensino de Filosofia na formação dos adolescentes consiste no fato de ela ser uma atividade capaz de levá-los a buscar e a adotar, de uma maneira consciente, livre e autônoma, os sentidos norteadores de suas vidas, dotando-os de instrumentos pelos quais eles possam fazer uma leitura do mundo de uma maneira crítica e não subserviente.

Não seria um exagero dizer que esse papel a ser desempenhado pela Filosofia, assim como pela Sociologia na formação dos jovens não se aplica apenas ao jovem enquanto tal, mas desempenha um importante papel nos demais estágios da vida humana, sobretudo na velhice, uma vez que essa não traz consigo necessariamente a sabedoria, como se o seu conceito fosse um conceito analítico (cujo predicado - a sabedoria - estivesse contido no conceito sujeito - velhice). A experiência que a velhice traz consigo não se confunde necessariamente com a sabedoria. Podemos ser experientes em algumas coisas e, no entanto, não sermos sábios nas mesmas. A sabedoria implica numa atitude ética. A velhice, inevitavelmente, traz consigo rugas e cabelos brancos, mas a sabedoria, ela mesma, precisa ser constantemente cultivada pelo autoexame, pela autorreflexão, o que implica numa atitude de constante mudança e atenção em face às próprias atitudes e aos princípios que orientam as próprias ações, do contrário correr-se o risco de se cometer sérias injustiças ao se confundir a experiência com a sabedoria.

Uma das belas passagens da Filosofia, a qual ilustra um pouco disso que acabamos de dizer, encontra-se na "Carta sobre a felicidade" do filósofo Epicuro a seu discípulo Meneceu, na qual o filósofo exorta sobre o exercício da Filosofia cuja finalidade é tornar feliz aquele que a ela se dedica, "de tal modo que este deve cultivá-la durante o transcurso de sua existência, desde a mais tenra juventude até a idade mais avançada":

Que ninguém hesite em se dedicar à filosofia enquanto jovem, nem se canse de fazê-lo depois de velho, porque ninguém jamais é demasiado jovem ou demasiado velho para alcançar a saúde do espírito. Quem afirma que a hora de dedicar-se à filosofia ainda não chegou, ou que ela já passou, é como se dissesse que ainda não 
chegou ou que já passou a hora de ser feliz. Desse modo, a filosofia é útil tanto ao jovem quanto ao velho [...] (EPICURO, 2002, p. 21-23).

Por tudo o que vimos até aqui, ainda que uma das especificidades da Filosofia seja a sua relação com o conceito, relação de análise, elucidação e até mesmo "criação de conceitos", segundo o filósofo contemporâneo Deleuze, essa reflexão conceitual, todavia, não se encerra num plano meramente abstrato e nem num domínio puramente especulativo. À medida que essa reflexão se volta para as questões que surgem na nossa experiência com o mundo concreto, podemos dizer que a reflexão filosófica tem por finalidade compreender as condições, limites e possibilidades dessa experiência em todas as suas dimensões, dotando-nos de uma visão mais aguçada sobre a vida. Agora, para isso, certamente, é preciso um recuo do mundo concreto para melhor compreendê-lo, como quando queremos olhar nossos óculos para vê-los melhor precisamos retirá-los da nossa face e distanciá-lo de nossos olhos, assim também é a nossa relação com o mundo da nossa experiência concreta. Mas, como não podemos sair do mundo sensível para melhor enxergá-lo, uma vez que somos seres sensíveis, podemos realizar esse distanciamento a partir do pensamento. É por meio do pensamento, da reflexão, que a Filosofia se propõe a compreender as questões que a nossa razão levanta. Contudo, esse recuo pelo pensamento se volta para as próprias questões despertadas a partir do mundo concreto da nossa experiência.

A não compreensão da sua real utilidade acabou por levar a Filosofia, muitas vezes, a ser taxada de um saber distante da vida concreta dos seres humanos, sendo o filósofo considerado um "homem alienado", que vive no "mundo das nuvens", sem se preocupar com a vida cotidiana. Sabemos da anedota contada a respeito daquele que é considerado o pai da Filosofia, Tales de Mileto, que, certa vez, ao cair num buraco, foi ridicularizado por sua escrava que jocosamente comentou: "eis aí um homem que anda com os olhos fixados nas nuvens e esquece de olhar para o chão onde pisa".

O que é preciso deixar claro quando se pretende argumentar porque a Filosofia é importante para a formação dos jovens, sua utilidade e sua relevância para a vida humana, consiste na afirmação de que a atividade da Filosofia, como bem caracterizou Aristóteles, não consiste em dotar os seres humanos de habilidades, mecanismos ou de técnicas inovadoras para solucionar os problemas imediatos do cotidiano, como por exemplo, a de criar máquinas de descascar e cortar batatas de uma maneira rápida e segura, ou coisa que o valha.

Entretanto, quando dizemos que a utilidade da Filosofia não consiste em se alcançar resultados imediatos - na medida em que não nos oferece instrumentos para a resolução de problemas do cotidiano - não queremos, com isso, afirmar que ela seja um saber em si mesmo inútil, mas sim que ela possui uma finalidade cujo valor para a vida humana vai além das necessidades imediatas do cotidiano e que, em função disso, não pode ser vista como um saber meramente visado em vista da produção de algum objeto ou da inovação de algum produto a ser usado como meio. É nesse sentido que devemos aos filósofos gregos a distinção entre o conceito de finalidade e o conceito de utilidade. $O$ bem, o qual era considerado como o fim de todos os seres, fim visado com a realização máxima das faculdades ou capacidades humanas, não se confunde com o útil. Aquilo que não tem utilidade do ponto de vista das necessidades cotidianas, não é, por isso, desprovido de finalidade. A finalidade da Filosofia, nesse sentido, era a de conduzir à realização máxima do bem a que os seres humanos estavam destinados. 
O valor intrínseco da Filosofia para a vida humana consiste em fazer com que os seres humanos possam escolher livre e conscientemente os princípios em função dos quais poderão orientar suas vidas no mundo, ou seja, sentidos, conceitos e valores que vão constituir o seu caráter. Além disso, a dimensão de esclarecimento e elucidação crítica proporcionados pela experiência filosófica a respeito do sentido das coisas, das nossas vivências e das propostas massificadoras de "modos de vida" que se apresentam para serem seguidos, é o meio pelo qual podemos assumir uma atitude livre e autônoma em face a essas propostas.

Foi com esse sentido compartilhado a respeito da relevância da Filosofia para a formação dos adolescentes que, segundo os Professores Danilo Marcondes e Irley Franco, o Relatório da Real Comissão de Investigação sobre o Ensino da província de Québec publicou um texto em favor da inclusão da Filosofia no currículo escolar. No texto, afirma-se que:

Aquele que for iniciado em filosofia será mais consciente e mais livre; habituado a refletir e reexaminar os problemas, não cederá facilmente às propagandas, aos movimentos coletivos impensados, mas saberá se situar no mundo, na sociedade [...]. Saberá tomar decisões com maior lucidez e liberdade [...] (Apud MARCONDES; FRANCO, 2011, p. 14).

Kant atribuiu dois sentidos ao conceito "filosofia: um do ponto de vista das escolas (sentido escolástico), mais voltado à sistematização dos princípios do conhecimento humano do real; e outro sentido da "filosofia" que, por se referir "aos fins últimos da razão humana" diz respeito à todos os seres humanos. Esse é o sentido da "filosofia" segundo o seu "conceito do mundo", ou seu "sentido cosmopolita" e que, por se referir a uma sabedoria prática, estaria ligada diretamente às ações humanas que, como ética, "é a ideia de uma sabedoria perfeita que nos mostra os fins últimos da razão humana". ${ }^{3}$

Esse é um dos pontos em que a Filosofia se distingue das outras disciplinas, marcando, assim, sua especificidade com relação às demais, pois, ainda que o pensamento e a reflexão não sejam apenas atributos da Filosofia, a reflexão nela operada é de natureza bastante peculiar, reflexão conceitual que visa a encontrar os fundamentos e princípios próprio para a possibilidade das diversas experiências, e, na medida em que essa reflexão se volta eminentemente para as questões que a razão humana levanta, essas se referem aos fins essenciais da humanidade, dotando-nos de uma postura autônoma e, porque não dizer, ética, em face do mundo. Com esse pensamento, acreditamos, por fim, que a Filosofia

habitua a inteligência a refletir com rigor e precisão sobre as questões mais fundamentais da vida humana, tornando-a autônoma, livre das forças materiais que cada vez mais a pressionam (MARCONDES; FRANCO, 2011, p. 14).

\section{CONSIDERAÇÕES FINAIS}

Diante do que foi exposto, e se ainda nos resta algum fio de esperança que num mundo marcado pela massificação em série, ainda seja possível a formação de jovens capazes de refletir e deliberar com autonomia e liberdade, isso pode ser um sinal de que o papel e a relevância desempenhados pela Sociologia e pela Filosofia não podem ser contidos nos estreitos limites de

${ }^{3}$ Cf. KANT, I. Lógica, Ak 24, p. 41. 
uma racionalidade instrumental e mesmo pragmática que reduz a formação humana a valores da eficácia e da utilidade imediata. $\mathbf{O}$ valor e a relevância de ambas as disciplinas são para a vida como um todo e não para uma parte dela.

Nessa medida, a Sociologia e a Filosofia, enquanto atividades reflexivas, não podem ser vistas como disciplinas inúteis, abstratas e, ainda por cima, de difícil acesso. Ao contrário, elas possuem uma contribuição muito própria à formação ética dos jovens na medida em que oferece a esses os elementos necessários para a autonomia do seu pensamento por meio do exercício crítico do mesmo e para a formação de uma cidadania cujo sentido é ao mesmo tempo ético e político, ou seja, o sentido marcado por uma preocupação, responsabilidade e atitude para com a vida no mundo. Tarefa que, na contracorrente do tempo presente, profundamente marcado pelos ideais da produção e consumo de bens, dos modelos programados de vida, do egocentrismo, é um desafio a ser enfrentado por todo educador comprometido com os princípios de uma formação autenticamente humana. Eis a relevância do ensino da Sociologia e da Filosofia para uma educação que se propõe a construir consciências críticas e éticas, ao invés de meros autômatos programados para produzir e consumir.

\section{REFERÊNCIAS}

1. BRASIL, Ministério da Educação. Secretaria de Educação Básica. Orientações Curriculares para o Ensino Médio. v. 3. Brasília: Ministério da Educação, 2006.

2. CANDIDO, Antônio. Vários escritos. 3. ed. São Paulo: Duas Cidades, 1995.

3. EPICURO. Carta sobre a felicidade: a Meneceu. Tradução e apresentação: Álvaro Lorencini e Enzo Del Carratore. São Paulo: Editora Unesp, 2002.

4. FREIRE, Paulo. Pedagogia do Oprimido. 41. ed. Rio de Janeiro: Paz e Terra, 2005.

5. GALLO, S.; ASPIS. R. L. Ensinar Filosofia: um livro para professores. São Paulo: Atta, Mídia e Educação, 2009.

6. GUIMARÃES, Elisabeth da Fonseca. Epistemologia e cidadania: o ensino de Sociologia na Educação Básica. In: VIEIRA, José Glebson; CUNHA (Org.). Desafios e perspectivas do ensino e da formação de professores de Sociologia para o Ensino Médio. Mossoró/RN: UERN, 2014, p. 17-33.

7. IGLESIAS, Maura. O que é filosofia e para que serve. In: REZENDE, Antonio (Org.) Curso de Filosofia. 13. ed. Rio de Janeiro: Jorge Zahar Editor, 2003.

8. KANT, Immanuel. Lógica. 3. ed. Trad. Guido Almeida. Rio de Janeiro: Tempo Brasileiro, 2003.

9. MARCONDES, D.; FRANCO, I. A filosofia: o que é para que serve?. Rio de Janeiro: Jorge Zahar, PUC-Rio, 2011.

10. MILLS, C. W. A imaginação sociológica. 6. ed. Rio de Janeiro: Zahar Editores, 1982.

11. NIETZSCHE, F. Escritos sobre educação. Trad. Noéli Sobrinho. Rio de Janeiro: Loyola, PUC-Rio, 2004.

12. SANTOS, Boaventura de Sousa. Conhecimento prudente para uma vida decente: "um discurso sobre as ciências revisitado". 2. ed. São Paulo: Cortez, 2006.

13. VIEIRA, J. G.; CUNHA, L. A. Apresentação: o ensino de Sociologia na pauta da UERN. In: VIEIRA, José Glebson; CUNHA (Org.). Desafios e perspectivas do ensino e da formação de professores de Sociologia para o Ensino Médio. Mossoró/RN: UERN, 2014, p. 7-16. 